\section{THU0186 RHEUMATOID ARTHRITIS AND INTERSTITIAL LUNG DISEASE. MULTICENTRIC RETROSPECTIVE STUDY OF 118 PATIENTS TREATED WITH BIOLOGICAL NO ANTI TNF}

C. Fernández-Díaz ${ }^{1}$, S. Castañeda ${ }^{2}$, B. Garcia-Magallon ${ }^{3}$, J. Narvaez-García ${ }^{4}$ M. Retuerto ${ }^{1}$, T. Perez-Sandoval ${ }^{5}$, M. Martin-Lopez ${ }^{1}$, P. Rubio-muñoz ${ }^{6}$, M. Carrasco-Cubero ${ }^{7}$, D. Reina-Sainz ${ }^{8}$, A. Urruticoechea ${ }^{9}$, C. Ojeda-Garcia ${ }^{10}$ S. Rodriguez-Muguruza ${ }^{11}$, P. Carreira ${ }^{1}$, L. Belmar-Vega ${ }^{12}$, E. Cervantes ${ }^{13}$ B. Robles-flores ${ }^{14}$, L. Arboleya ${ }^{15}$, G. Bonilla ${ }^{16}$, I. Hernandez-Rodriguez ${ }^{17}, \mathrm{O}$. Maiz Alonso $^{18}$, D. Palma ${ }^{19}$, C. Delgado ${ }^{20}$, R. Expósito-Molinero ${ }^{21}$, F. Ortiz-Sanjuan ${ }^{22}$, A. Ruibal-Escribano ${ }^{23}$, S. Ordoñez ${ }^{24}$, M. Moreno ${ }^{25}$, I. Villa blanco ${ }^{26}$, C. Fito ${ }^{27}$. J. Blanco-Madrigal ${ }^{28}$, J. Bernal ${ }^{29}$, S. Romero ${ }^{30}$, N. Mena-Vazquez ${ }^{31}$, M. Lopezcorbeto ${ }^{32}$, T.J. Mas ${ }^{33}$, T.R. Vazqzez ${ }^{34}$, M.A. Gonzalez-Gay ${ }^{12}$, R. Blanco ${ }^{12} .{ }^{1} \mathrm{H} .12$ de Octubre; ${ }^{2} \mathrm{H}$. Princesa; ${ }^{3} \mathrm{H}$. San Jorge, Madrid; ${ }^{4} \mathrm{H}$. Bellvitge, Barcelona; ${ }^{5} \mathrm{H}$., León; ${ }^{6} \mathrm{H}$., Badalona; ${ }^{7}$ H., Badajoz; ${ }^{8} \mathrm{H}$. Boggi, Barcelona; ${ }^{9} \mathrm{H}$., Ibiza

${ }^{10} \mathrm{H}$. Macarena, SevillJ. Bernala. ${ }^{11} \mathrm{H}$. Germans Trias, Barcelona; ${ }^{12} \mathrm{H}$. Valdecilla, Santander, ${ }^{13} \mathrm{H}$., Santiago; ${ }^{14} \mathrm{H}$. Puerta del Hierro, Madrid; ${ }^{15} \mathrm{H}$., Oviedo; ${ }^{16} \mathrm{H}$. La Paz, Madrid; ${ }^{17} \mathrm{H}$., Vigo: ${ }^{18} \mathrm{H}$., Donostia; ${ }^{19} \mathrm{H}$. Lorca; ${ }^{20} \mathrm{H}$. Blesa, Zaragoza; ${ }^{21} \mathrm{H}$., Laredo; ${ }^{22} \mathrm{H}$. La Fe, Valencia; ${ }^{23} \mathrm{H}$., Vitoria; ${ }^{24} \mathrm{H}$., Pontevedra; ${ }^{25} \mathrm{H}$. Arrixaca, Murcia ${ }^{26} \mathrm{H}$., Torrelavega; ${ }^{27} \mathrm{H}$., Navarra; ${ }^{28} \mathrm{H}$. Basurto, Bilbao; ${ }^{29} \mathrm{H}$., Alicante; ${ }^{30} \mathrm{H}$., Lleida; ${ }^{31} \mathrm{H}$., Malaga; ${ }^{32} \mathrm{H}$. Vall d'Hebron, Barcelona; ${ }^{33} \mathrm{H}$. Palma, Palma de Mallorca; ${ }^{34} \mathrm{H}$. Lugo, Lugo, Spain

Background: Interstitial lung disease (ILD) associated with Rheumatoid Arthritis (RA) has a poor prognosis. Treatments such as anti-TNF, have been implicated in the exacerbation of an ILD.

Objectives: Our objective is to evaluate and compare the evolution of ILD in patients with RA treated with Abatacept (ABA), Rituximab (RTX) and Tocilizumab (TCZ) after 1 year of treatment.

Methods: Retrospective multicentre study of patients with ILD and AR treated with ABA, RTX and TCZ at standard doses. The ILD was diagnosed by CT. The efficacy was evaluated whith the following measures: i) Dyspnea by modified scale of the Medical Research Council (mMRC); considering variations of 1 point. ii) Respiratory function tests; considering variations in FVC and DLCO $\geq 10 \%$. iii) Imaging test (CT).

Results: We included 118 (72 women/46 men) patients, mean age of 62.27 \pm 10.55 years. The ILD had a median evolution of $1212-37$ months. The RA was ACPA+in 102 cases (86.4\%). At diagnosis, the mean DLCO onset of biological treatment was $65.63 \pm 19.38$. Table 1 shows the characteristics by subgroups. The Figure expresses the evolution in the cases available at 12 months. There is an improvement in $\mathrm{CT}$ in $36.4 \%$ of patients with $\mathrm{ABA}, 28.6 \%$ of patients with RTX and only $8.3 \%$ of patients with TCZ.

Abstract THU0186 - Table 1

\begin{tabular}{lcccc}
\hline & ABA & RITU & TCZ & p \\
\hline AGE median years & $65(57-70)$ & $64(54,75-$ & $60(48-$ & 0.187 \\
& & $72)$ & $68,5)$ & \\
SEX M/F & $36 / 27$ & $21 / 9$ & $15 / 10$ & 0490 \\
SMOKER OR EX-SMOKER Si/No & $25 / 38$ & $13 / 17$ & $11 / 14$ & 0909 \\
APCC+ & 85,7 & 90 & 84 & 0776 \\
BIOLOGICAL DMARD BEFORE\% & 44.4 & 30 & 60 & 0084 \\
DLCO Onset & 64.76 & 67.52 & 65.58 & 0.854 \\
& \pm 15.93 & \pm 23.4142 & \pm 22.700 & \\
CT & $29 / 34$ & $14 / 16$ & $11 / 14$ & 0677 \\
UIP/OTHERS & 87.09 & $87.83 \pm 23.14$ & 80.38 & 0.178 \\
FVC at star & \pm 15.56 & & \pm 27.79 & \\
& $12(12-$ & $15(5,75-$ & $10(3-10)$ & 0875 \\
MONTHS OF EVOLUTION OF & $36,75)$ & $37,75)$ & & \\
PNEUMONITIS & \multicolumn{3}{c}{} \\
\hline
\end{tabular}

*p significant $<0,05$

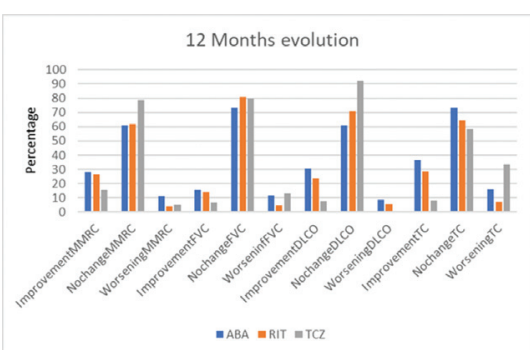

Conclusions: There seems to be a trend towards a better radiological response in patients treated with RTX and ABA. It would be necessary prospective studies.

Disclosure of Interest: None declared

DOI: 10.1136/annrheumdis-2018-eular.4986

\section{THU0187 \\ CIRCULATING AUTOANTIBODIES AS INDICATORS TO PREDICT THE CLINICAL RESPONSE TO INFLIXIMAB IN RHEUMATOID ARTHRITIS}

L. Lourido $^{1,2,3}$, C. Ruiz-Romero ${ }^{1,4}$, F. Picchi ${ }^{1}$, E. Pérez-Pampín ${ }^{5}$, C. Regueiro ${ }^{2,5}$, A. Mera-Varela ${ }^{5}$, A. Gonzalez ${ }^{2,5}$, K. Hambardzumyan ${ }^{6}$, S. Saevarsdottir 6 ,

P. Nilsson ${ }^{3}$, F.J. Blanco ${ }^{1,2} .{ }^{1}$ Rheumatology Division, ProteoRed/ISCIII Proteomics Group, INIBIC - Hospital Universitario de A Coruña, A Coruña; ${ }^{2}$ RIER-RED de Inflamación y Enfermedades Reumáticas, Madrid, Spain; ${ }^{3}$ Affinity Proteomics, SciLifeLab, School of Biotechnology, KTH - Royal Institute of Technology, Stockholm, Sweden; ${ }^{4}$ CIBER-BBN Instituto de Salud Carlos III, Madrid; ${ }^{5}$ Laboratorio Investigacion 10 and Rheumatology Unit, Instituto de Investigacion Sanitaria-Hospital Clinico Universitario de Santiago, Santiago de Compostela, Spain; ${ }^{6}$ Unit of Rheumatology, Department of Medicine, Karolinska Institutet and Rheumatology Clinic, Karolinska University Hospital, Stockholm, Sweden

Background: Approximately a third of Rheumatoid Arthritis (RA) patients treated with tumour necrosis factor (TNF)- $\alpha$ inhibitors such as Infliximab (IFX) fail to respond. This has prompted a widespread interest in the finding of measures for predictors of response to TNF $\alpha$ inhibitors.

Objectives: To search for serum autoantibodies that aid to identify RA patients most likely to benefit from IFX.

Methods: We analysed serum of 170 biologic-naïve RA patients at baseline assigned to receive IFX plus methotrexate. The serum samples were distributed in 3 independent samples sets that were provided by 3 different sources: 1 discov ery sample set $(n=24)$ collected from Hospital Clínico Universitario of Santiago de Compostela (Spain) and 2 validation sample sets collected from Hospital Universitario de A Coruña (Spain), ( $n=61)$; and the Swedish Farmacotherapy (SWEFOT) trial (Sweden), $(n=85)$. The European League Against Rheumatism (EULAR) criteria were used to assess the clinical response at six months of follow-up: good response ( $G R, n=60)$, moderate $(M R, n=60)$ and non-response $(N R, n=50)$. A suspension bead array platform built on protein fragments within Human Protein Atlas and selected from an initial screening using an array containing 42000 antigens was employed to identify the $\lg \mathrm{G}$ and $\lg \mathrm{A}$ autoantibodies in the discovery sample set and validate the results within the 2 validation sets. Thresholds for autoantibodies were calculated by Receiver Operating Characteristics (ROC) curve analy sis performed with SPSS 24

Results: Our data revealed a more prevalent IgG reactivity and higher IgG autoantibody levels against the antigen Centromere Protein F (CENPF) in GR when compared with NR, showing an overall reactivity of $31 \%$ vs $0 \%, 45 \%$ vs. $26 \%$ and $17 \%$ vs $4 \%$ in the three sample sets analysed respectively. The area under the ROC curve was 0,649 [p-value $=0.049$; IC 95\% (0.510-0.789)]. CENP-F is a proliferation-associated and cell cycle-dependent centromere autoantigen that might be involved in the increased or abnormal cell proliferation that occurs during RA process. Interestingly, our results also showed that $\lg A$ autoantibodies levels toward the antigen Solute Carrier family 39 member 2 (SLC39A2), a zinc transporter protein, were decreased in GR when compared with MR in the discovery sample set and this trend was significantly validated $(p=0.018)$ in the SWEFOT cohort. The area under the ROC curve was 0,681 [p-value=0,019; IC95\% $(0,543$ 0,818)].

Conclusions: We have identified two autoantibodies in RA that associate with IFX response. Our findings could potentially be useful to guide the treatment decisions for IFX and lead to further studies focusing on the role of the autoantibodies against CENPF and SLC39A2 within RA.

Disclosure of Interest: None declared

DOI: 10.1136/annrheumdis-2018-eular.6268

\section{THU0188 EFFICACY OF INFLIXIMAB FOR SUPPRESSING RADIOGRAPHIC PROGRESSION OF CERVICAL LESIONS IN PATIENTS WITH RHEUMATOID ARTHRITIS COMPARISON WITH METHOTREXATE; THREE YEARS OF FOLLOW-UP A MULTICENTER REGISTRY STUDY}

Y. Kanayama ${ }^{1}$, T. Kojima ${ }^{2}$, Y. Hirano ${ }^{3}$, N. Takahashi ${ }^{2}$, N. Ishiguro ${ }^{2}$, on behalf of TBCR study group. 'Orthopedic Surgery And Rheumatology, TOYOTA KOSEI HOSPITAL, Toyota; ${ }^{2}$ Orthopedic Surgery, Nagoya University Graduate School of Medicine, Nagoya; ${ }^{3}$ Rheumatology, Toyohashi Municipal Hospital, Toyohashi, Japan

Background: Cervical lesions are known to occur at high frequency as a complication of rheumatoid arthritis (RA). Treatment with biological agents are more clinically effective than the DMARDs that were in use previously, in particular, with their efficacy in suppressing joint destruction having been emphasised. We reported the efficacy of infliximab (IFX), anti-tumour necrosis factor antibodies for suppressing the radiographic progression of RA cervical lesions at ACR2009, EULAR2010,11, 12, 13, 14 and 16. However there is still few studies of efficacy of against RA cervical lesions of IFX comparison with methotrexate(MTX).

Objectives: To evaluate the efficacy of IFX for suppressing the radiographic progression of RA cervical lesions comparison with MTX for 3 years. 
Methods: We used MTX or MTX +IFX for treating Japanese patients with active RA who fulfilled the ACR criteria in 1987. The final study cohort of each 64 and 70 patients received continuous MTX and IFX treatment for at least 3 years. MTX was used in all patients receiving IFX. For evaluation of cervical lesions, the atlanto-dental interval (ADI), the space available for the spinal cord (SAC), and the Ranawat value were measured by plain lateral radiographs in the flexion position, at initiation, Year 1, 2 and 3.

Results: In the patients receiving MTX $(n=64)$ and IFX $(n=70)$, the number of female were each $46(72 \%)$ and $60(86 \%)$ cases $(p=0.049)$. The mean age was $63.4 \pm 11.0$ and $54.2 \pm 12.8$ years old $(p<0.001)$; disease duration was $8.5 \pm 9.8$ and $10.5 \pm 9.3$ years $(p=0.027)$ and the mean dose of MTX was $7.9 \pm 2.8$ and 7.5 $\pm 1.7 \mathrm{mg} / \mathrm{w}(\mathrm{p}=0.607)$. Clinical findings related to RA were as follows; CRP 1.5 \pm 2.1 and $3.3 \pm 3.0 \mathrm{mg} / \mathrm{dl}(\mathrm{p}<0.001) ; \quad E S R \quad 29.9 \pm 21.1$ and $54.9 \pm 23.9 \mathrm{~mm} / \mathrm{h}$ $(p<0.001)$; MMP3 $223 \pm 373$ and $355 \pm 328 \mathrm{ng} / \mathrm{ml}(\mathrm{p}<0.001)$; DAS28 $4.21 \pm 1.35$ and $5.43 \pm 1.29(\mathrm{p}<0.001) ; \mathrm{ADI} 2.7 \pm 1.6$ and $3.4 \pm 1.7 \mathrm{~mm}(\mathrm{p}=0.005)$; $\mathrm{SAC} 20.7 \pm 2.6$ and $18.4 \pm 2.5 \mathrm{~mm}(p<0.001)$ and Ranawat value $15.9 \pm 1.5$ and $14.5 \pm 2.3 \mathrm{~mm}$ $(p<0.001)$. The respective changes in cervical lesion parameters after 3 years were as follows: $A D I$ : $0.70 \pm 0.77$ and $0.47 \pm 0.74 \mathrm{~mm}(\mathrm{p}=0.042)$; $\mathrm{SAC}$ : -0.69 \pm 0.85 and $-0.44 \pm 0.79 \mathrm{~mm} \quad(p=0.043)$; and Ranawat value: $-0.48 \pm 0.69$ and $-0.34 \pm 0.51 \mathrm{~mm}(\mathrm{p}=0.359)$ between MTX and IFX patients (figure 1). The numbers of patients who did not showed progression in ADI, SAC and Ranawat value were each $30(47 \%)$ vs $45(64 \%)$ cases $(\mathrm{p}=0.043) ; 33(52 \%)$ vs $48(69 \%)$ cases $(p=0.044)$ and $40(63 \%)$ vs $47(67 \%)$ cases $(p=0.574)$ after 3 years. Also the number who was able to suppress progression in all three parameters were each 30 cases $(47 \%)$ receiving MTX and 39 cases $(56 \%)$ receiving IFX ( $p=0.307)$ after 3 years (figure 2 ).

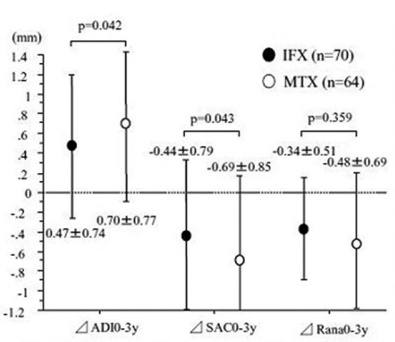

1 . Figure 1 : Respective changes in ADI, SAC and Ranawat
value from Year 0 to Year 3 between MTX and IFX patients

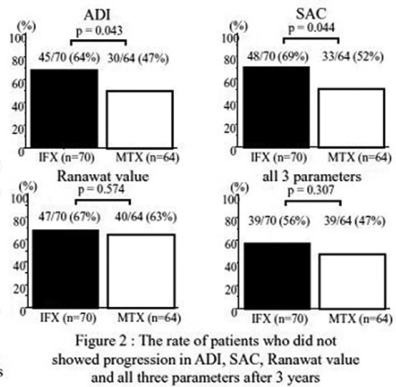

and all three paran, SAC, Ranawat
Abstract THU0188 - Figure 1. Respective changes in ADI, SAC and Ranawat value from Year 0 to Year 3 between MTX and IFX patients. Abstract THU0188 - Figure 2. The rate of patients who did not showed progression in ADI, SAC, Ranawat value and all three parameters after 3 years

Conclusions: This study suggested that IFX treatment can be used to suppress the progression of RA cervical lesions more than MTX treatment.

Disclosure of Interest: Y. Kanayama: None declared, T. Kojima Speakers bureau: Mitsubishi Tanabe Pharma, Takeda Pharma, Eisai Pharma, AbbVie, Bristol-Myers Squibb, and Pfizer, Janssenn Pharmaceutical Companies, Astellas Pharma and Chugai Pharma., Y. Hirano Speakers bureau: Abbvie Japan, Eisai, Mitsubishi Tanabe Pharma, Pfizer, Chugai Pharmaceutical, and Bristol-Myers Squibb., N. Takahashi Speakers bureau: Abbvie Japan Co. Ltd, Eisai Co. Ltd, UCB Japan Co. Ltd, Mitsubishi Tanabe Pharma Corporation, Takeda Pharmaceutical Company Ltd, Pfizer Co. Ltd, Chugai Pharmaceutical Co. Ltd, Janssen Pharmaceutical K.K., and Bristol-Myers Squibb Co. Ltd., N. Ishiguro Grant/ research support from: Daiichi Sankyo, Takeda Pharmaceutical, Hisamitsu Pharmaceutical, Otsuka Pharmaceutical, Taisho Toyama Pharmaceutical, Kaken Pharmaceutical, Eisai, Janssen Pharmaceutical, Bristol-Myers Squibb, AbbVie, Chugai Pharmaceutical, Mitsubishi Tanabe Pharmaceutical, Astellas Pharma, and Pfizer Japan, Speakers bureau: Daiichi Sankyo, Takeda Pharmaceutical, Hisamitsu Pharmaceutical, Otsuka Pharmaceutical, Taisho Toyama Pharmaceutical, Kaken Pharmaceutical, Eisai, Janssen Pharmaceutical, Bristol-Myers Squibb, AbbVie, Chugai Pharmaceutical, Mitsubishi Tanabe Pharmaceutical, Astellas Pharma, and Pfizer Japan.

DOI: 10.1136/annrheumdis-2018-eular.6462

\section{THU0189 \\ ONE-YEAR TREATMENT RETENTION AFTER A NATIONWIDE NON-MEDICAL SWITCH FROM ORIGINATOR TO BIOSIMILAR ETANERCEPT IN 2,061 PATIENTS WITH INFLAMMATORY ARTHRITIS FOLLOWED IN THE DANBIO REGISTRY}

B. Glintborg, I.J. Sørensen, E. Omerovic, F. Mehnert, N. Manilo, K. Danebod, D. V. Jensen, H. Nordin, A.G. Loft, O. Hendricks, S. Chrysidis, B.L. Andersen, J.

L. Raun, H. Lindegaard, J. Espesen, S.H. Jakobsen, I.M.J. Hansen, E.

B. Dalsgaard, D.D. Pedersen, S. Kristensen, A. Linauskas, L.S. Andersen,

J. Grydehøj, N. Krogh, M.L. Hetland. The DANBIO registry and the Danish

Departments of Rheumatology, Copenhagen, Denmark

Background: In Denmark, rheumatoid arthritis(RA), psoriatic arthritis(PsA) and axial spondyloarthritis(AxSpA) patients (pts) treated with originator etanercept (ETA) $50 \mathrm{mg}$ SC conducted a mandatory non-medical switch to biosimilar Etanercept (SB4) in April 2016 (switchers). Pts treated with $25 \mathrm{mg}$ ETA or $50 \mathrm{mg}$ powder solution were not mandated to switch (non-switchers).

Objectives: To characterise switchers and non-switchers, and to compare 1 year treatment retention in switchers with non-switchers and a historic cohort of ETA treated pts.

Methods: Pt data were retrieved from the DANBIO registry and national registries. We applied Chi-square/Mann-Whitney for comparisons and Kaplan-Meier/ Cox regression analyses (crude, adjusted for gender/age/MTX/remission/comorbidities/ETA-start-year) for drug retention. The historic cohort encompassed pts treated with ETA by Jan 1 st 2015.

Results: Of 2,061 ETA treated pts by April 2016, 79\% switched to SB4 (933RA/ $351 \mathrm{PsA} / 337 \mathrm{AxSpA}$ ), whereas $21 \%$ (286RA/56PsA/98AxSpA) continued ETA. In RA, compared to switchers, non-switchers more often received $25 \mathrm{mg}$ ETA, had higher disease activity and $\mathrm{HAQ}$ (table 1). Similar patterns were seen for PsA and AxSpA. Median(IQR) follow-up was 383(314-414)days. In all 3 cohorts, withdrawals were mainly due to lack of effect. Retention rate was lowest in non-switchers (figure 1). 1 year adjusted rates were $83 \%(95 \% \mathrm{Cl} 79-87)$ in switchers, $77 \%$ ${ }^{72-82}$ in non-switchers and $90 \%\left({ }^{88-92}\right.$ in historic cohort. Pts not in remission had poorer retention than pts in remission both in switchers (hazard ratio 1.7 (1.3-2.2) and non-switchers (2.4 (1.7-3.6)).

Numbers are medians (IQR) unless otherwise stated. * DAS28 <2.6 (RA, PsA) ASDAS $<1.3(\mathrm{AxSpA})$

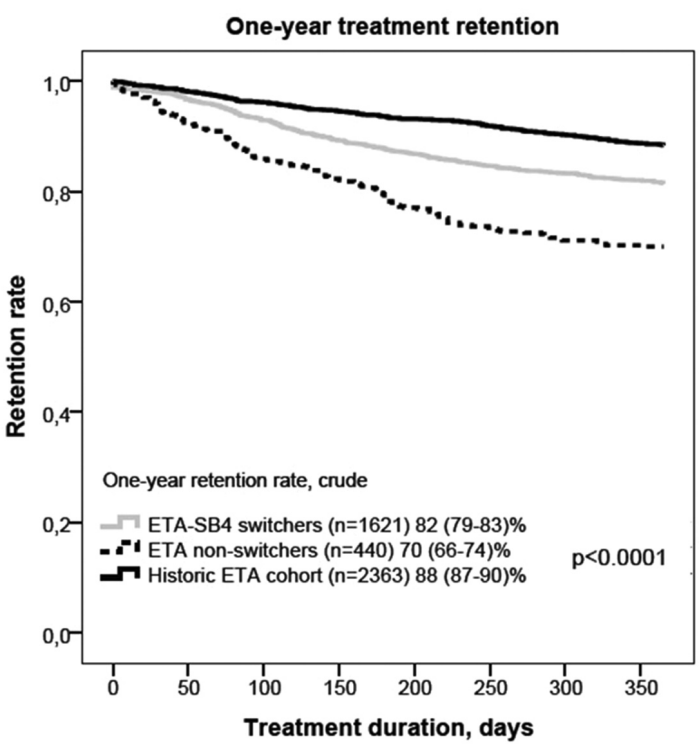

Conclusions: Of $>2000$ ETA treated pts, $\approx 80 \%$ switched to SB4. Non-switchers had higher disease activity and more often received $25 \mathrm{mg}$ ETA. Switchers had poorer retention rate than a historic ETA-cohort, but better than non-switchers. Withdrawal was most common in pts not in remission. These real-world data indicate that a switching-to-biosimilar option facilitated clinical decision making in 